\title{
Undernutrition and elevated blood lead levels: effects on psychomotor development among Jamaican children
}

\author{
Julie Meeks Gardner ${ }^{1, *}$, Susan P Walker ${ }^{1}$, Susan M Chang ${ }^{1}$, Mitko Vutchkov ${ }^{2}$ and \\ Gerald C Lalor ${ }^{2}$ \\ 'Tropical Metabolism Research Unit, University of the West Indies, Mona, Kingston 7, Jamaica, West \\ Indies: ${ }^{2}$ International Centre for Environmental and Nuclear Sciences, University of the West Indies, \\ Mona, Kingston 7, Jamaica, West Indies
}

Submitted 27 March 1998: Accepted 22 April 1998

\begin{abstract}
Objective: We examined whether or not the effect of elevated blood lead levels on children's psychomotor development was modified by their nutritional status.

Design: Anthropometry, developmental quotients (DQs), blood lead levels and haemoglobin were measured in lead exposed and unexposed children with different levels of nutritional status. Social background and maternal height and verbal intelligence were also measured. Testers, anthropometrists and interviewers established reliabilities with a trainer before the study began.

Setting: Children were from two suburban areas in Kingston, Jamaica. All measurements on the children were carried out at a research unit. Social background and maternal measurements were carried out at the children's homes.

Subjects: The exposed group comprised 58 children (3-6 years) attending the same preschool which was situated in a lead contaminated environment. The unexposed group comprised 53 children attending a nearby preschool without lead contamination.

Results: The exposed children had significantly higher blood lead levels and lower DQs, and their homes had poorer facilities than the unexposed children. The deficit in DQ was greater (10.6 points) among children with weight for height less than $-1 \mathrm{SD}$ (National Center for Health Statistics references) than among better nourished children ( 2 points).

Conclusions: Undernourished children exposed to lead may have more serious developmental deficits than better nourished children.
\end{abstract}

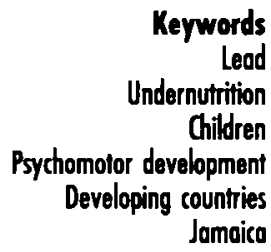

Undernutrition remains an important public health problem in developing countries ${ }^{1}$. Many researchers have demonstrated an association between undernutrition and poor psychomotor development in young children ${ }^{2}$, and poor levels of intelligence and school achievement in later childhood. In countries with high levels of undernutrition, this has serious implications for national development.

Additionally, several longitudinal studies indicate that prenatal and childhood exposure to lead is associated with deficits in children's cognition ${ }^{3-7}$, although some controversy remains over the magnitude of the effects ${ }^{8}$. These studies have generally been conducted in developed countries and often with groups of middle to high socioeconomic status. In one study with lowincome families in the USA, interaction with socioeconomic status suggested that the effects of lead may be greater in children from poorer families?

The problem of lead pollution is now greatest in the rapidly expanding cities in developing countries where the use of lead in petrol remains the norm ${ }^{9}$. Undernutrition is also common in the under- 5 population in many of these countries ${ }^{1}$ and it is possible that undernourished children may be more vulnerable to lead exposure than well-nourished children. There is, however, a lack of data to address this question as little of the research concerning lead and development has been conducted in developing countries. The aim of this study was to compare the psychomotor development of preschool children in a lead contaminated community in Kingston, Jamaica with that of children in a control community and to determine whether the effect of lead on development was modified by the children's nutritional status.

\section{Methods}

The sample comprised children who attended a preschool (school KT) which was located on a site contaminated with lead waste and undifferentiated ore 
grade material from a nearby defunct lead mine ${ }^{10}$ and where the children were living in a high lead contaminated environment. All children aged 3-6 years attending the school, whose parents gave informed consent, and who had no obvious mental or physical handicap were included ( $n=58,26$ boys). The sample comprised $92 \%$ of children attending the school in the age group. A comparison group of all available children from a preschool in an adjacent community (school AT) were also recruited ( $n=53,25$ boys). The soil lead levels at this school were within the normal background levels for Jamaica ${ }^{11}$ and the comparison community was ranked immediately above the lead exposed community according to the poverty index of the Planning Institute of Jamaica ${ }^{12}$.

The children's developmental quotients (DQs) were measured using five subscales of the Griffith's Mental Development Scales-locomotor, hand and eye, hearing and speech, practical reasoning and performance ${ }^{13}$-by one of two testers. Intertester reliability was established before the study began (concurrent agreement on 11 children $=99 \%$ ), and each tested a similar proportion of children from both groups. Anthropometric measurements were taken using standard techniques ${ }^{14}$ and interobserver reliabilities were high $(r=0.99)$. Haemoglobin measurements were made using a Hemocue ${ }^{15}$. Capillary blood samples from a fingerprick were collected on filter paper for subsequent lead content analysis at LeadTech Corporation, New Jersey, using micro blood techniques $^{16,17}$. Special care was taken to avoid contamination. The children's hands were washed by an investigator immediately prior to the fingerprick blood collection, according to the protocol provided by LeadTech Corporation, dried with a paper towel, and did not touch any surface or objects before the samples were taken. All measurements on the children were conducted at the Tropical Metabolism Research Unit.

The children's homes were visited and their caretakers were given a questionnaire to assess their social background. The standard of housing was rated on a nine-point scale in which equal weight was given to water supply, toilet facilities and level of crowding. Household possessions were scored as the sum of the presence of a stove (oil, gas or electric), television, radio and refrigerator (range 0-4). Environmental stimulation was measured using a modified version of the Bettye Caldwell Home Observation for Measurement of the Environment (HOME) inventory ${ }^{18}$, and caretakers' verbal intelligence was measured using the Peabody Picture Vocabulary test (PPVT) ${ }^{19}$. All home interviews were carried out by a single researcher whose concurrent agreement with the trainer on 20 interviews before the study began was $98 \%$.

Approval for the study was granted by the Jamaican Ministry of Education, and the Ethical Committee of the University of the West Indies.
Table 1 Developmental levels, social background, nutritional status and blood lead levels of children in school KT (exposed) and school AT (unexposed)

\begin{tabular}{|c|c|c|c|c|}
\hline & \multicolumn{2}{|c|}{ School KT } & \multicolumn{2}{|c|}{ School AT } \\
\hline & Mean & SD & Mean & SD \\
\hline $\mathrm{DQ}$ & 94.0 & 11.0 & 98.7 & $10.8^{*}$ \\
\hline Housing rating & 5.0 & 2.0 & 6.6 & $1.8^{* *}$ \\
\hline No. of possessions & 2.8 & 1.1 & 3.1 & 1.0 \\
\hline Caretaker's PPVT & 90.5 & 20.8 & 98.7 & 24.6 \\
\hline HOME & 21.2 & 5.5 & 21.4 & 5.6 \\
\hline Height for age (z-score) & -0.3 & 0.9 & -0.04 & 1.0 \\
\hline Weight for height (z-score) & -0.3 & 0.9 & -0.1 & 0.8 \\
\hline Haemoglobin $\left(\mathrm{g} \mathrm{dl}^{-1}\right)$ & 11.3 & 1.4 & 11.5 & 1.2 \\
\hline $\operatorname{Lead}\left(\mu \mathrm{g} \mathrm{dl}{ }^{-1}\right)$ & 32.0 & 13.7 & 13.5 & $5.2^{\star *}$ \\
\hline
\end{tabular}

t-test * $P<0.05, \cdots P<0.001$

Statistical analyses were conducted using the SPSS for Windows statistical package.

\section{Results}

The children's characteristics and social background are shown in Table 1. The children in school KT had significantly lower DQs and came from homes with poorer facilities than the children from school AT. None of the remaining social background variables were significantly different between the groups and there were also no significant differences in nutritional status. As expected the blood lead levels were significantly higher in the children attending school KT.

Multiple regression analyses were conducted to determine the effect of lead exposure on the children's developmental levels controlling for social background, and to examine possible interactions between the measures of nutritional status (height for age, weight for height, haemoglobin) and lead exposure. Children who attended school KT were the exposed group and the children in school AT were the unexposed group. Separate regression analyses were conducted for each of the nutritional variables. In each, the children's age and sex were entered and the following social background variables were offered: housing rating, possessions, caretaker's PPVT and stimulation (HOME). Although some of the social background variables were not significantly different between the groups they were included as potential confounders as they have been shown to be important in other studies of lead and cognition. In the final step, school attended, the measure of nutritional status and the interaction term were entered.

The multiple regression model including weight for height and the interaction term with lead exposure is shown in Table 2. Among children with weight for height $\leq-1 \mathrm{SD}^{20}$ the DQs of children in school AT (unexposed) were 10.6 points higher than those in school KT $(P<0.05)$. However, in children with better nutritional status (weight for height $>-1$ SD) the 
Table 2 Multiple regression of DQ on child characteristics, social background ${ }^{\mathrm{a}}$ and lead exposure

\begin{tabular}{lrcc}
\hline Variable & B & SE & $P$ \\
\hline Age (mo) & -0.36 & 0.07 & 0.001 \\
Sex & 2.02 & 1.71 & 0.24 \\
No. of possessions & 2.70 & 0.84 & 0.01 \\
HOME $^{\text {School }}$ & 0.36 & 0.16 & 0.05 \\
Weight for height $^{c}$ & 10.57 & 4.42 & 0.05 \\
Weight for height $^{\text {(n) school }}$ & 2.07 & 2.87 & 0.47 \\
\end{tabular}

Social background variables offered: housing rating, possessions, caretaker's PPVT, HOME. 'School KT (exposed) $=0$, school AT (unexposed) $=1$.

${ }^{c}$ Weight for height $z$-score $\leq-1=0,>-1=1$

difference was only $2 \mathrm{DQ}$ points. In a regression excluding weight for height and the interaction term, the difference between the schools was 3.2 points $(P=0.058)$. There were no significant interactions of lead exposure with height for age or haemoglobin levels.

\section{Discussion}

Our results suggest that lead exposure may be more detrimental to undernourished children's development compared with adequately nourished children. The overall effect of lead in this study was comparable to that reported elsewhere ${ }^{21,22}$, and was greater in children with weight for height below $-1 \mathrm{SD}$. This cut-off indicates only mild wasting so the difference may be greater in children with severe nutritional deficits.

There were some limitations to the study: the sample size was small, although it comprised almost the entire exposed population. The study design would also have been stronger if it had been possible to recruit exposed and unexposed children from the same school. However, almost all of the children at school KT had elevated blood lead levels, and the comparison group had to be found from another school.

The interaction effect which indicated that the undernourished children were more vulnerable to the effects of elevated blood lead levels was only marginally significant, and the finding needs replication elsewhere. If confirmed, and undernourished children are more vulnerable to lead exposure, the increasing problems with lead pollution in developing countries become of even greater public health significance.

\section{Acknowledgements}

This study was supported by the Environmental Foundation of Jamaica. The blood lead analyses were carried out by the LeadTech Corporation, North Bergen, New Jersey. We thank S Hutchinson and $V$ Reid for assistance; and the Ministry of Education, the school principals and parents for their cooperation and support.

\section{References}

1 UNICEF. The State of the World's Children 1998. Oxford: Oxford University Press, 1998.

2 Grantham-McGregor S. Recent advances in research on mental development and protein energy malnutrition. In: Walqvist $M$ et al., eds. Nutrition in a Sustainable Entironment. Proceedings of the XVth International Congress of Nutrition. UK: Smith-Gordon, 1994.

3 Fergusson DM, Horwood LJ, Lynskey MT. Early dentine lead levels and subsequent cognitive and behavioural development. J. Child. Psycbol. Psychiatr. 1993; 34: 215-27.

4 Wasserman G, Graziano JH, Factor-Litvak P, et al. Independent effects of lead exposure and iron deficiency anemia on development outcome at age 2 years. J. Pediatr. 1992; 121: 695-703.

5 Baghurst PA, McMichael AJ, Wigg NR, et al. Environmental exposure to lead and children's intelligence at the age of seven years. N. Engl. J. Med. 1992; 327: 1279-84.

6 Bellinger D, Sloman J, Leviton A, Rabinowitz M, Needleman HL, Waternauz C. Low-level lead exposure and children's cognitive function in the preschool years. Pediatrics 1991; 87: 219-27.

7 Dietrich KN, Krafft KM, Bornschein RL, et al. Low-level fetal lead exposure effect on neurobehavioral development in early infancy. Pediatrics $1987 ; 80$ : 721-30.

8 Cunningham RD. Skeptical about importance of low levels of lead. Pediatrics 1993; 91 : 1214.

9 Pearce F. A heavy responsibility. New' Scientist 1996; July 27 : 12-13.

10 Anglin-Brown B, Armour-Brown A, Lalor GC. Heavy metal pollution in Jamaica 1: Survey of cadmium, lead and zinc concentrations in the Kintyre and Hope Flat districts. Environ. Geochem. Health 1995; 17: 51-6.

11 Johnson A, Lalor GC, Preston J, Vutchkov MK. Heavy metal pollution in Jamaica 2: Background levels of lead in Jamaican soils. Jamaican J. Sci. Tech, in press.

12 Policy Development Unit. Poverty Mapping: A Report on the Spatial Representation of Deprivation in Jamaica. Kingston, Jamaica: Planning Institute of Jamaica, 1996.

13 Griffiths R. The Abilities of Young Children. London: Child Development Research Centre, 1970.

14 Lohman TG, Roche AF, Martorell R. Antbropometric Standardization Reference Manual. Champaign, II: Human Kinetics Books, 1988.

15 Hudson-Thomas $M$, Bingham KC, Simmonds WK. An evaluation of the Hemocue for measuring haemoglobin in field studies in Jamaica. Bull. WHO 1994; 72: 423-6.

16 Vereby K, Eng YM, Davidow B, Ramon A. Rapid sensitive micro blood lead analysis: a mass screening technique for lead poisoning. J. Analyt. Toxicol. 1991; 15: 237-40.

17 Rosen JF, Schonfeld DJ, Carriero D, et al. Blood collection and analytical considerations in blood lead screening in children. Clin. Chem. 1995; 41: 469-70.

18 Bradley RH, Caldwell BM. Home Observation for Measurement of the Environment: a validation study of screening efficiency. Am. J. Mental Deficiency 1977; 81: 417-20.

19 Dunn LM, Dunn LM. Peabody Picture Vocabulary TestRevised. Nashville, TN: American Guidance Service, 1982.

20 National Center for Health Statistics, Centers for Disease Control. NCHS Growth Curves for Children, Birtb to 18 Years. Washington, DC: US Govt. Printing Office 1978. [Series 11, 165. DHEW Publication 78, 1650.]

21 Needleman HL, Gastonis CA. Low-level lead exposure and the IQ of children. J. Am. Med. Assoc. 1990; 263: 673-8.

22 Smith MA. The effects of low-level lead exposure on children. In: Smith MA, Grant LD, Sors AI, eds. Lead Exposure and Child Development, an International Assessment. Dordrecht: Kluwer Academic, 1989, 3-47. 